\title{
Growth studies of erbium-doped GaAs deposited by metalorganic vapor phase epitaxy using novel cyclopentadienyl-based erbium sources
}

\author{
J. M. Redwing and T. F. Kuech \\ Department of Chemical Engineering, University of Wisconsin, Madison, Wisconsin 53706 \\ D. C. Gordon and B. A. Vaartstra \\ Advanced Technology Materials, Inc., Danbury, Connecticut 06810 \\ S. S. Lau \\ Deparimeni of Electrical and Computer Engineering, Universily of California, San Diego, \\ La Jolla, California 92093
}

(Received 7 March 1994; accepted for publication 28 April 1994)

\begin{abstract}
Erbium-doped GaAs layers were grown by metalorganic vapor phase epitaxy using two new sources, bis( $i$-propylcyclopentadienyl)cyclopentadienyl erbium and tris( $t$-butylcyclopentadienyl) erbium. Controlled Er doping in the range of $10^{17}-10^{18} \mathrm{~cm}^{-3}$ was achieved using a relatively low source temperature of $90^{\circ} \mathrm{C}$. The doping exhibits a second-order dependence on inlet source partial pressure, similar to behavior obtained with cyclopentadienyl $\mathrm{Mg}$ dopant sources. Equivalent amounts of oxygen and Er are present in "as-grown" films indicating that the majority of Er dopants probably exist as Er-O complexes in the material. $\mathrm{Er}^{3+}$ luminescence at $1.54 \mu \mathrm{m}$ was measured from the as-grown films, but ion implantation of additional oxygen decreases the emission intensity. Electrical compensation of $n$-type $\mathrm{GaAs}$ layers codoped with $\mathrm{Er}$ and $\mathrm{Si}$ is directly correlated to the Er concentration. The compensation is proposed to arise from deep centers associated with Er which are responsible for a broad emission band near $0.90 \mu \mathrm{m}$ present in the photoluminescence spectra of GaAs:Si, Er films.
\end{abstract}

\section{INTRODUCTION}

The doping of semiconductors with optically active rare earths can provide sharp, temperature independent luminescence arising from the internal $f$-shell transitions of the rareearth ion which are screened from the host lattice. The rareearth ion, $\mathrm{Er}^{3+}$, is of particular interest due to its radiative $4 f$-electron intrashell transition, ${ }^{4} I_{13 / 2} \rightarrow{ }^{4} I_{15 / 2}$. This transition emits photons with a wavelength of $1.54 \mu \mathrm{m}$, corresponding to a low loss transmission window of silica-based optical fibers. The incorporation of $\mathrm{Er}^{3+}$ in III-V semiconductors, such as GaAs, offers the potential of combining the atomic-like emission characteristics of $\mathrm{Er}^{3+}$ with the ability to activate the rare-earth transitions via electrical pumping of the host semiconductor. Er-doped GaAs optoelectronic devices, such as light emitting diodes and lasers, can therefore be envisioned for use in a variety of optical communication. applications.

The development of Er-based devices hinges on the ability to efficiently incorporate optically active $\mathrm{Er}^{3+}$ ions into the host semiconductor material. A number of techniques have been used to dope $\mathrm{Er}$ in GaAs with varying degrees of success. The low solid solubility of $\mathrm{Er}$ in $\mathrm{GaAs}\left(\sim 10^{17}\right.$ $\mathrm{cm}^{-3}$ ) limits the Er concentration that can be obtained in near-equilibrium growth by liquid phase epitaxy. ${ }^{1}$ High levels of Er have been achieved through ion implantation. ${ }^{2}$ The depth of the doped region, however, is limited to the very near-surface region using moderate implant energies due to the high Er mass. Molecular beam epitaxy (MBE) ${ }^{3}$ and metalorganic vapor phase epitaxy (MOVPE), ${ }^{4}$ which are growth techniques far from equilibrium, have both been used successfully to obtain a wide range of Er concentrations in III-V semiconductors. MBE requires the use of elemental erbium which is highly reactive and difficult to purify. MOVPE, on the other hand, typically utilizes cyclopentadienyl (Cp) Er complexes to transport $\mathrm{Er}$ to the growth front. These $\mathrm{Er}$ sources offer the potential of increased purity and reduced reactivity during storage due to the stabilizing effect of the cyclopentadienyl ligands. ${ }^{5}$

One drawback to the use of Er cyclopentadienyl dopant sources is their low volatility. Most Er sources have a vapor pressure in the range of $0.1-1.0$ Torr at $200^{\circ} \mathrm{C} .{ }^{6}$ For the case of $\mathrm{Cp}_{3} \mathrm{Er}$, its low vapor pressure necessitates the use of extremely high bubbler temperatures $\left(\sim 200^{\circ} \mathrm{C}\right)$ and leads to unintentional impurity incorporation as well as difficulties in obtaining reproducible doping levels. ${ }^{7}$ Increased vapor pressures have been obtained by replacing a hydrogen on the $\mathrm{Cp}$ rings $\left(\mathrm{C}_{5} \mathrm{H}_{5}^{+}\right)$with a methyl or $i$-propyl group, similar to techniques used to modify the vapor pressure and melting point of $\mathrm{Mg}$ cyclopentadienyl compounds. ${ }^{8}$ The deposition of Er-doped GaAs layers by MOVPE has been demonstrated by a number of groups using $(\mathrm{Cp})_{3} \mathrm{Er}^{4}{ }^{4}$ (methylCp) ${ }_{3} \mathrm{Er}^{9}$ ( $i$-propylCp) ${ }_{3} \mathrm{Er},{ }^{10}$ and $\left(n\right.$-butylCp) ${ }_{3} \mathrm{Er}^{11}$ sources. These studies have focused primarily on evaluating the Er doping process through an examination of the optical properties of the material. Although the Er-related photoluminescence spectra have been reported to be very sensitive to MOVPE growth conditions, ${ }^{9}$ the effect of growth conditions on the rate of Er incorporation from these cyclopentadienyl compounds has not been investigated in detail.

In this study; we have synthesized two new sources with differing $\mathrm{Cp}$ alkyl ligand structures, ( $i$-propylCp) ${ }_{2} \mathrm{CpEr}$ $\left[\left(\mathrm{C}_{3} \mathrm{H}_{7} \mathrm{C}_{5} \mathrm{H}_{4}\right)_{2}\left(\mathrm{C}_{5} \mathrm{H}_{5}\right) \mathrm{Er}\right] \quad$ and $(t \text {-butylCp })_{3} \mathrm{Er}$, $\left[\left(\mathrm{C}_{4} \mathrm{H}_{9} \mathrm{C}_{5} \mathrm{H}_{4}\right)_{3} \mathrm{Er}\right]$. These moderate vapor pressure sources ${ }^{12}$ were used to obtain Er concentrations in the range of 
$10^{17}-10^{18} \mathrm{~cm}^{-3}$ at a relatively low Er bubbler temperature of $90^{\circ} \mathrm{C}$. The effect of MOVPE growth conditions on Er doping was investigated with an aim toward understanding the role of cyclopentadienyl-based chemistry in the doping process. Er and $\mathrm{Mg}$ cyclopentadienyl dopant sources exhibit similar incorporation behavior indicating that source chemistry does strongly influence the doping efficiency in both cases. Er doping was found to introduce donor compensating deep level centers into GaAs layers codoped with $\mathrm{Si}$. The impact of these centers on the electrical and optical properties of the material is presented here.

\section{EXPERIMENTAL METHODS}

The (i-propylCp) ${ }_{2} \mathrm{CpEr}$ was prepared by reaction of $\mathrm{NaCp}$ with ( $i$-propylCp) ${ }_{2} \mathrm{ErCl}$ [obtained from reaction of $\mathrm{ErCl}_{3}$ with $\mathrm{Na}$ (i-propylCp)]. The $(t \text {-butylCp })_{3} \mathrm{Er}$ was prepared by the reaction of $\mathrm{ErCl}_{3}$ with excess $(t$-butylCp) $\mathrm{K}$. Both reactions were carried out in tetrahydrofuran solution and the products purified by vacuum sublimation $\left(10^{-4} \mathrm{Torr}\right)$ at 130 and $150^{\circ} \mathrm{C}$, respectively. The compounds are waxy orange solids, melting near $90^{\circ} \mathrm{C}$. The composition of each compound was verified by elemental analysis. Although the vapor pressures of the two sources have not been precisely measured, the ( $i$-propylCp) ${ }_{2} \mathrm{CpEr}$ source is expected to have a higher vapor pressure due to its lower sublimation temperature. Both compounds were used as liquids at a bubbler source temperature of $90^{\circ} \mathrm{C}$.

Erbium-doped epitaxial GaAs films were grown at 78 Torr in a horizontal MOVPE reactor using trimethylgallium $\left[\left(\mathrm{CH}_{3}\right)_{3} \mathrm{Ga}\right.$ or TMGa] and $\mathrm{AsH}_{3}$. Palladium purified $\mathrm{H}_{2}$ was used as the carrier gas. The inlet mole fraction of TMGa was $1.9 \times 10^{-4}$ which corresponds to a GaAs growth rate of $\sim 0.05 \mu \mathrm{m} / \mathrm{min}$. The growth temperature was varied over the range $600-750{ }^{\circ} \mathrm{C}$ and the $\mathrm{V} / \mathrm{III}$ ratio $\left(\mathrm{AsH}_{3} / \mathrm{TMGa}\right)$ was varied from 30 to 120 . The Er source was heated to $90^{\circ} \mathrm{C}$ and the lines downstream of the Er bubbler were heated to $100{ }^{\circ} \mathrm{C}$ to prevent condensation of the dopant source. The mole fraction of ( $i$-propylCp $)_{2} \mathrm{CpEr}$ and $\left(t\right.$-butylCp) ${ }_{3} \mathrm{Er}$ in the inlet gas was not precisely known, but was considered to be in the range of $\sim 1 \times 10^{-5}$ based on our estimated vapor pressure. $^{12}$ The Er gas phase mole fraction was varied over one order of magnitude by changing the $\mathrm{H}_{2}$ flow rate through the Er bubbler from 20 to $200 \mathrm{sccm}$. Several of the GaAs: $\mathrm{Er}$ layers were codoped with $\mathrm{Si}$ using $\mathrm{Si}_{2} \mathrm{H}_{6}$ to a $\mathrm{Si}$ concentration of $3.5 \times 10^{17} \mathrm{~cm}^{-3}$ for use in subsequent electrical characterization of the films. Multilayer samples were grown in which the growth temperature, V/III ratio, or Er precursor mole fraction were varied in a stepwise fashion every $0.5 \mu \mathrm{m}$ of $\mathrm{GaAs}$ growth.

The incorporation of $\mathrm{Er}$, as well as $\mathrm{Si}$ and oxygen, was studied through the use of secondary ion mass spectrometry (SIMS) using $\mathrm{Cs}^{+}$as the primary ion for $\mathrm{Si}$ and $\mathrm{O}$ detection and $\mathrm{O}_{2}^{+}$for Er. Electrochemical capacitance profiling was used to measure the electron concentration in the GaAs films codoped with Si and Er. Low-temperature (12.K) photoluminescence measurements were made using the $514 \mathrm{~nm}$ line of an $\mathrm{Ar}^{+}$laser as the excitation source. The luminescence was dispersed with a $1 \mathrm{~m}$ monochromator and focused onto a cooled $(77 \mathrm{~K}) \mathrm{Ge}$ detector. Several of the Er-doped GaAs

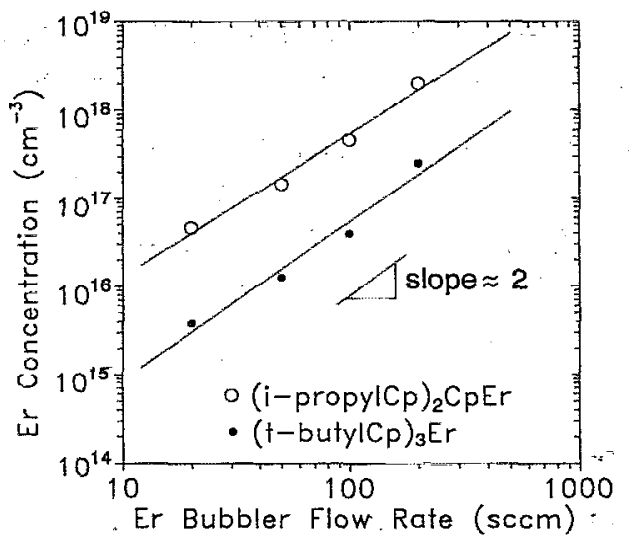

FIG. 1. The Er concentration in MOVPE GaAs films, [Er $]_{\text {GaAs }}$, doped using the $\left(t\right.$-butylCp) ${ }_{3} \mathrm{Er}$ and ( $i$-propylCp) ${ }_{2} \mathrm{CpEr}$ sources increases superlinearly with an increase in the $\mathrm{H}_{2}$ flow rate through the $\mathrm{Er}$ bubbler, where $[\mathrm{Er}]_{\mathrm{GaAs}} \propto X_{\mathrm{Er}}^{n}$ and $n \cong 2 . X_{\mathrm{Er}}$, the inlet mole fraction of the Er source, is proportional to the bubbler flow rate.

films were implanted with additional oxygen in order to investigate its effect on the $\mathrm{Er}^{3+}$ emission intensity. The films were implanted with $\mathrm{O}^{+}$using a dose of $2.5 \times 10^{14} / \mathrm{cm}^{2}$ at an energy of $160 \mathrm{keV}$ followed by a $7.0 \times 10^{13} / \mathrm{cm}^{2}$ dose at 60 $\mathrm{keV}$ to give an $\mathrm{O}$ concentration of $\sim 1 \times 10^{19} \mathrm{~cm}^{-3}$ at a depth of $1 \mu \mathrm{m}$. The $\mathrm{O}^{+}$implanted samples were proximity annealed at $800^{\circ} \mathrm{C}$ for $30 \mathrm{~s}$ using rapid thermal annealing. The annealing conditions chosen were similar to those reported in a previous study of oxygen implantation in $\mathrm{GaAs}^{13}$

\section{RESULTS}

\section{A. Growth and doping study}

Controlled $\mathrm{Er}$ doping of GaAs was achieved from both the ( $i$-propylCp $)_{2} \mathrm{CpEr}$ and $\left(t\right.$-butylCp) ${ }_{3} \mathrm{Er}$ sources using a constant Er bubbler temperature of $90^{\circ} \mathrm{C}$. The $\mathrm{Er}$ source mole fraction, growth temperature, and V/III ratio were varied independently in several of the growth runs in order to investigate the influence of MOVPE growth conditions on $\mathrm{Er}$ incorporation and to compare the two Er sources. The Er source mole fraction was varied, by changing the $\mathrm{H}_{2}$ bubbler carrier gas flow rate, to establish a relationship between the partial pressure of $\mathrm{Er}$ in the gas stream and the concentration of Er obtained in the solid film. The results of SIMS analysis of the Er concentration of these samples, grown at $650^{\circ} \mathrm{C}$ and a V/III ratio of 60 , are shown in Fig. 1. The ( $i$-propylCp $)_{2} \mathrm{CpEr}$ source results in an Er concentration that is. an order of magnitude greater than the $(t \text {-butylCp })_{3} \mathrm{Er}$ source, for a constant Er bubbler temperature. The Er concentration, $[\mathrm{Er}]_{\mathrm{GaAs}}$, follows a power-law dependence on the Er mole fraction, $X_{\mathrm{Er}}$, for both sources, where $[\mathrm{Er}]_{\mathrm{GaAs}}$ $\propto X_{\mathrm{Er}}^{n}$ and $n \cong 2$. SIMS depth profiles of the Er concentration of samples grown at a constant V/III ratio and $\mathrm{Er}$ mole fraction, with a varying growth temperature $\left(600-750^{\circ} \mathrm{C}\right)$, are shown in Fig. 2. The $\mathrm{Er}$ incorporation is independent of growth temperature for both sources over the temperature range investigated. The source of the dip in the Er level at the interface between the layers grown at 700 and $600{ }^{\circ} \mathrm{C}$, associated with the temperature change in the reactor, has not 


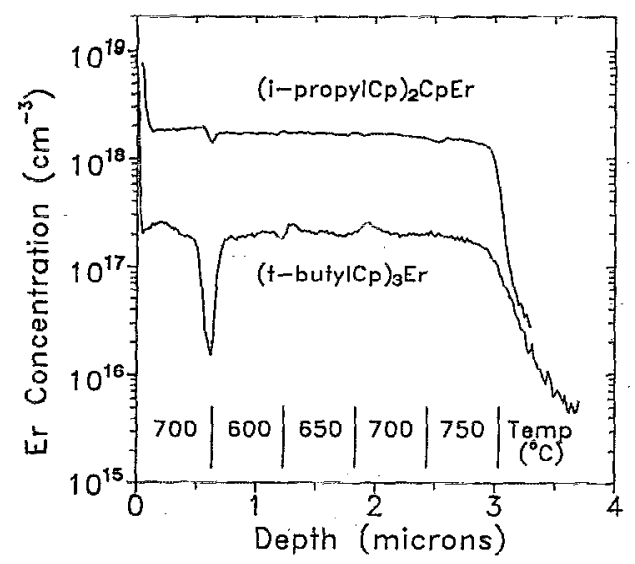

FIG. 2. SIMS depth profiles of the Er concentration in GaAs layers doped using the $(t \text {-butylCp })_{3} \mathrm{Er}$ and $(i \text {-propylCp})_{2} \mathrm{CpEr}$ sources show that the $\mathrm{Er}$ incorporation is independent of growth temperature over the range from 600 to $750^{\circ} \mathrm{C}$. The layers were grown at a constant Er mole fraction and V/III ratio (60). The origin of the dip in the Er level at the interface of the layers grown at 700 and $600{ }^{\circ} \mathrm{C}$ is not known, but is suspected to be an artifact of the growth or characterization method.

been identified but is likely an artifact of the growth or characterization process. The effect of V/III ratio on Er doping is shown in Fig. 3 for films grown at $650^{\circ} \mathrm{C}$ and a constant $\mathrm{Er}$ mole fraction. The Er concentration is not a function of the $\mathrm{V} / \mathrm{III}$ ratio when the ( $i$-propylCp $)_{2} \mathrm{CpEr}$ source is used, however, use of the $(t \text {-butylCp })_{3} \mathrm{Er}$ source results in a strong dependence on the V/III ratio. The Er concentration of the layers doped with the $(t \text {-butylCp })_{3}$ Er source decreases as the $\mathrm{AsH}_{3}$ concentration is raised and eventually drops below the SIMS detection limit when the V/III ratio is greater than 90 .

The concentration of $\mathrm{O}$ and $\mathrm{Si}$ in the Er-doped $\mathrm{GaAs}$ films was also measured and a representative SIMS depth profile is shown in Fig. 4. The Er concentration in this sample, also plotted in Fig. 1, was altered by varying the $\mathrm{H}_{2}$

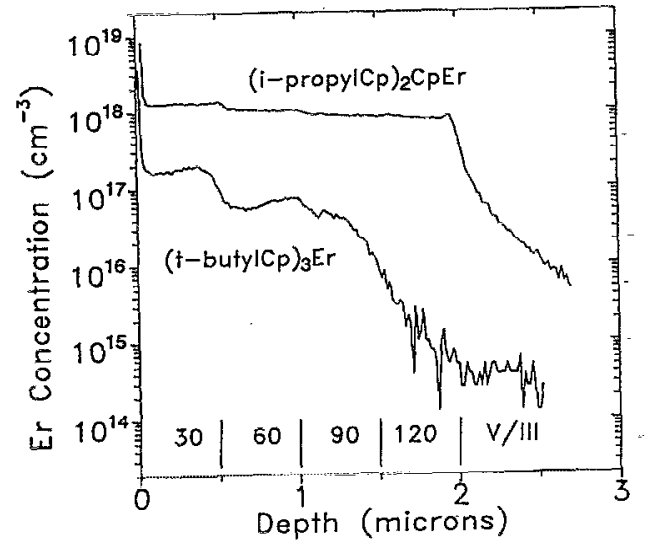

FIG. 3. SIMS depth profiles of the Er concentration in GaAs layers grown with varying $\mathrm{AsH}_{3}$ to TMGa (V/III) ratios show a significant difference in the effect of the V/III ratio on Er incorporation between the two Er sources. The V/III ratio was changed by varying the $\mathrm{AsH}_{3}$ concentration and using a constant TMGa mole fraction, Er source mole fraction, and growth temperature $\left(650^{\circ} \mathrm{C}\right)$. The Er doping is relatively insensitive to the V/III ratio when ( $i$-propylCp) ${ }_{2} \mathrm{CpEr}$ is used as the dopant source, but a strong dependence on the $\mathrm{AsH}_{3}$ concentration is observed with $(t \text {-butylCp })_{3} \mathrm{Er}$.

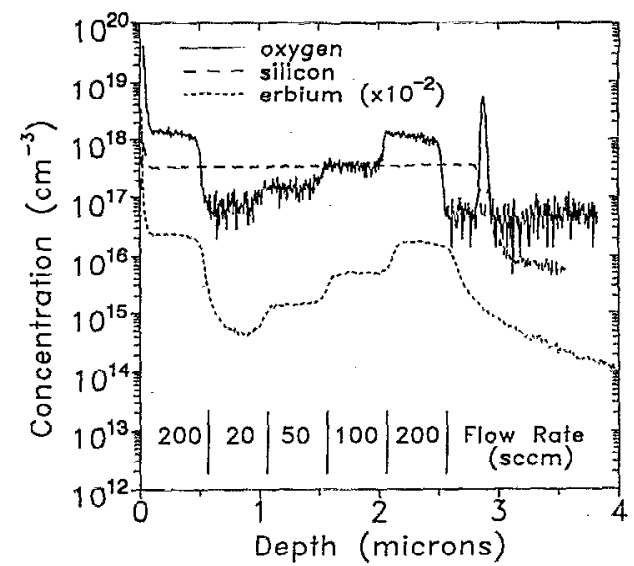

FIG. 4. Oxygen is incorporated into the Er doped GaAs films at an amount equivalent to the Er concentration as shown by the SIMS depth profile of the $\mathrm{O}$ and $\mathrm{Er}$ concentration in a layer grown with a varying flow rate of $\mathrm{H}_{2}$ through the ( $i$-propylCp) ${ }_{2} \mathrm{CpEr}$ bubbler. This film was grown at $650{ }^{\circ} \mathrm{C}$ with a V/III ratio of 60 . The layer was codoped with $\mathrm{Si}$ from $\mathrm{Si}_{2} \mathrm{H}_{6}$ to maintain a constant Si level of $\sim 3.5 \times 10^{17} \mathrm{~cm}^{-3}$.

flow rate through the ( $i$-propylCp) $)_{2} \mathrm{CpEr}$ bubbler. The $\mathrm{Si}$ incorporation in all of the samples was found to follow previously reported trends. ${ }^{14}$ Oxygen is incorporated in the Erdoped films during growth at an amount equivalent to the $\mathrm{Er}$ concentration. The Er profile shown in Fig. 4 is offset by a factor of $10^{-2}$, otherwise the oxygen and Er data would essentially overlap. The oxygen content of undoped GaAs films grown in our MOVPE system is well below the SIMS detection limit $\left(\sim 5 \times 10^{16} \mathrm{~cm}^{-3}\right)$ and significant oxygen incorporation is only observed in layers doped with Er.

\section{B. Electrical characterization}

The GaAs:Er films were codoped with Si in order to study the electrical properties of the layers. The $\mathrm{Er}, \mathrm{Si}$, and electron concentration of a GaAs film doped using the ( $i$-propylCp $)_{2} \mathrm{CpEr}$ source is shown in Fig. 5 as a function of

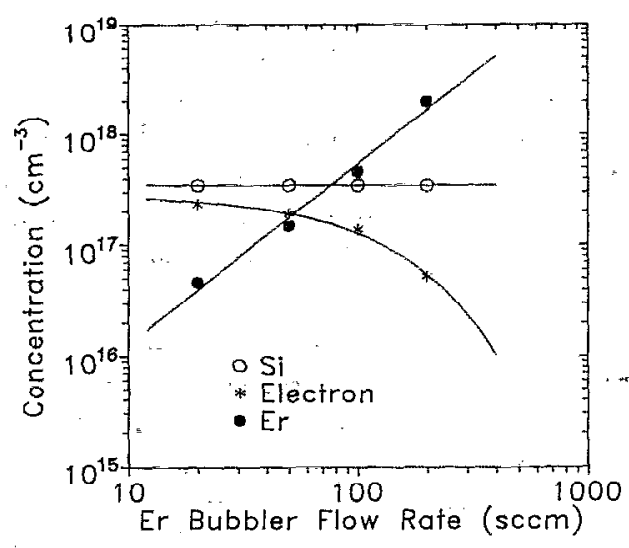

FIG. 5. Donor compensation is observed in GaAs layers codoped with $\mathrm{Si}$ and $\mathrm{Er}$ as shown by the decrease in the electron concentration of $n$-type layers as the amount of $\mathrm{Er}$ is increased. The $\mathrm{Er}$ and $\mathrm{Si}$ concentrations were measured using SIMS and electrochemical capacitance profiling was used to monitor the electron concentration. The GaAs:Er, Si film was grown at $650^{\circ} \mathrm{C}$ with a V/III ratio of 60 and the $\mathrm{H}_{2}$ flow rate through the Er bubbler was used to vary the ( $i$-propylCp) ${ }_{2} \mathrm{CpEr}$ mole fraction during growth. 


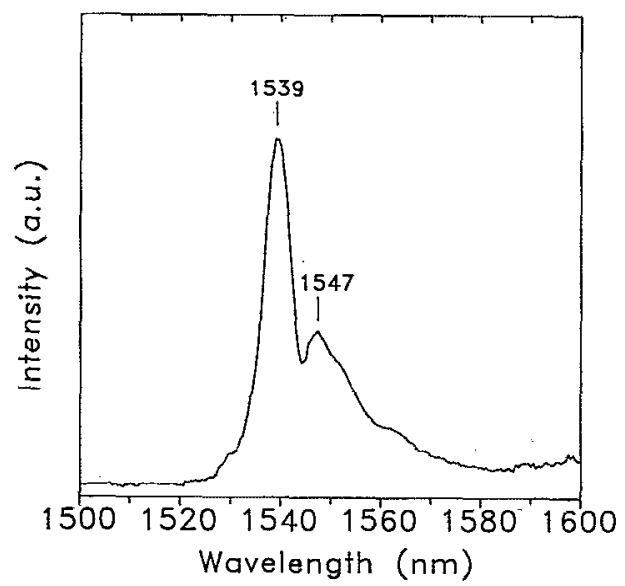

FIG. 6. The low-temperature $(12 \mathrm{~K})$ photoluminescence spectrum of a $\mathrm{GaAs}$ :Er film doped using ( $i$-propylCp) ${ }_{2} \mathrm{CpEr}$ contains characteristic $\mathrm{Er}^{3+}$ emissions at 1.539 and $1.547 \mu \mathrm{m}$. The PL measurements were obtained with a $514 \mathrm{~nm}$ excitation source at a power level of $10^{-7} \mathrm{~W} / \mathrm{m}^{2}$.

the $\mathrm{H}_{2}$ flow rate through the Er bubbler. The electron concentration is generally equivalent to the Si concentration in GaAs films grown under these conditions ${ }^{15}$ and, in the absence of electrically compensating centers, would be constant throughout the film and equal to the $\mathrm{Si}$ concentration $\left(\sim 3.5 \times 10^{17} \mathrm{~cm}^{-3}\right)$. The electron concentration, however, decreases as the Er concentration is raised almost two orders of magnitude. Donor compensation was observed in GaAs:Er films doped using both the $\left(t\right.$-butylCp) ${ }_{3} \mathrm{Er}$ and ( $i$-propylCp) ${ }_{2} \mathrm{CpEr}$ sources indicating that the compensating centers originate from either a deep level associated with $\mathrm{Er}$ itself, or an impurity or defect arising from the Er doping process. The compensation is roughly equal to the Er concentration at low levels, but saturates at $\sim 2 \times 10^{17} \mathrm{~cm}^{-3}$ at higher Er levels $\left(>3.5 \times 10^{17} \mathrm{~cm}^{-3}\right)$.

\section{Photoluminescence measurements}

A characteristic $\mathrm{Er}^{3+}$ emission spectrum obtained from $12 \mathrm{~K}$ photoluminescence (PL) measurements of a $\mathrm{GaAs}$ film doped with $\mathrm{Si}$ and $\mathrm{Er}$ using the (i-propylCp) ${ }_{2} \mathrm{CpEr}$ source is shown in Fig. 6. The spectrum contains an intense peak centered at $1.539 \mu \mathrm{m}$ accompanied by a broader band at 1.547 $\mu \mathrm{m}$. The $\mathrm{Er}^{3+}$ emission was present in all of the Er-doped films investigated and the principal spectral features were similar regardless of the $\mathrm{Er}$ dopant source. The use of $(t \text {-butylCp })_{3} \mathrm{Er}$, however, resulted in a lower $\mathrm{Er}^{3+}$ emission intensity than ( $i$-propylCp) ${ }_{2} \mathrm{CpEr}$, due to the lower Er concentration of the ( $t$-butylCp) $)_{3} \mathrm{Er}$ doped $\mathrm{GaAs}$ films.

The effect of $\mathrm{Si}$ codoping on the $12 \mathrm{~K}$ PL spectra of GaAs:Er films is shown in Fig. 7 for layers grown under similar MOVPE conditions. The PL spectrum of a GaAs:Er film, shown in Fig. 7(a), contains only $\mathrm{Er}^{3+}$ related emissions near $1.54 \mu \mathrm{m}$. GaAs band edge and carbon acceptor transitions near 0.82 and $0.83 \mu \mathrm{m}$, respectively, are present in the PL spectrum of a GaAs:Si $\left(n=2 \times 10^{16} \mathrm{~cm}^{-3}\right)$ layer, shown in Fig. 7(b). The spectrum of a GaAs:Er, Si layer, shown in Fig. 7(c), contains both GaAs band emission at $0.82 \mu \mathrm{m}$ and $\mathrm{Er}^{3+}$ peaks near $1.54 \mu \mathrm{m}$ as well as an intense emission band

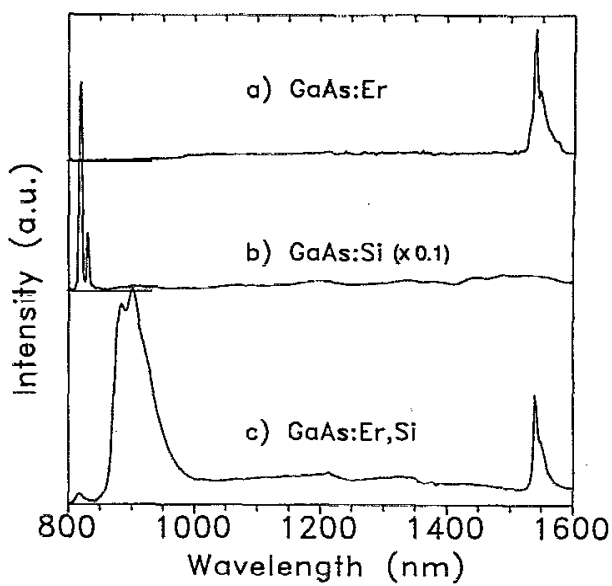

FIG. 7. The $12 \mathrm{~K}$ photoluminescence (PL) spectrum of a GaAs: $\mathrm{Er}$ film, shown in (a), contains only $\mathrm{Er}^{3+}$ related emissions near $1.54 \mu \mathrm{m}$ : GaAs band edge and carbon acceptor related emissions at 0.82 and $0.83 \mu \mathrm{m}$ are present in the PL spectrum of a GaAs:Si film shown in (b). The PL spectrum of a GaAs:Er, Si layer, shown in (c), contains GaAs band edge emission at $0.82 \mu \mathrm{m}$ and an intense band with peaks at 0.88 and $0.90 \mu \mathrm{m}$. The PL spectra were obtained using a $514 \mathrm{~nm}$ excitation source at a power level of $10^{-7} \mathrm{~W} / \mathrm{m}^{2}$.

with peaks at 0.88 and $0.90 \mu \mathrm{m}$. The 0.88 and $0.90 \mu \mathrm{m}$ recombinations are only observed in GaAs films codoped with both $\mathrm{Er}$ and $\mathrm{Si}$ and are present in layers grown with both the $(t \text {-butylCp })_{3} \mathrm{Er}$ and $(i \text {-propylCp})_{2} \mathrm{CpEr}$ sources. The $\mathrm{Er}^{3+}$ emission appears to be generally less intense in GaAs:Er, Si films than in GaAs films doped only with Er.

Oxygen was added to several of the GaAs:Er and GaAs:Er, Si films through $\mathrm{O}^{+}$ion implantation. The $\mathrm{Er}^{3+}$ emission spectrum of a $2.0 \mu \mathrm{m}$ GaAs:Er layer doped using the ( $t$-butylCp) ${ }_{3} \mathrm{Er}$ source, before and after $\mathrm{O}^{+}$implantation, is shown in Fig. 8. The $\mathrm{O}^{+}$implant dose was adjusted to give

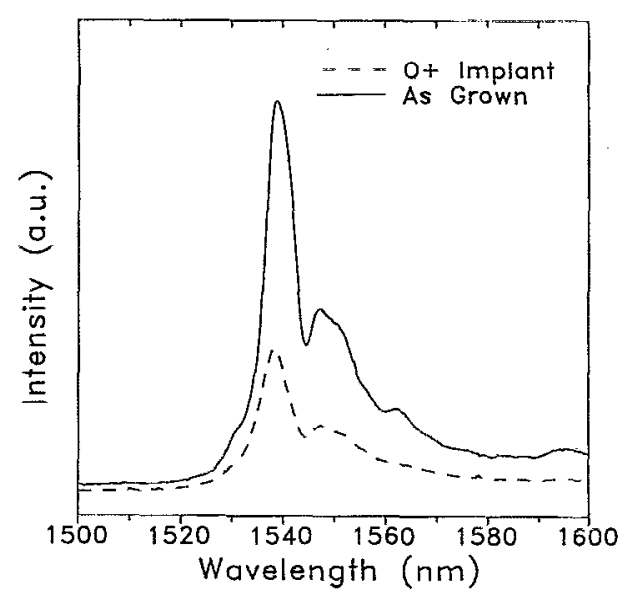

FIG. 8. The addition of oxygen, through $\mathrm{O}^{+}$implantation, results in a decrease in $\mathrm{Er}^{3+}$ related emission as shown by a comparison of the $12 \mathrm{~K} \mathrm{PL}$ spectrum of a GaAs:Er film before and after $\mathrm{O}^{+}$implantation. The as-grown GaAs: Er film was doped using the ( $t$-butylCp $)_{3} \mathrm{Er}$ source and was grown at $650^{\circ} \mathrm{C}$ with a V/III ratio of 60 . Ion implantation was used to obtain an $\mathrm{O}$ concentration of $\sim 1 \times 10^{19} \mathrm{~cm}^{-3}$ which is an order of magnitude greater than the $\mathrm{Er}$ concentration in the layer. The $\mathrm{O}^{+}$implanted films were proximity annealed at $800^{\circ} \mathrm{C}$ for $30 \mathrm{~s}$ to remove implantation damage. 
an oxygen concentration of $1 \times 10^{19} \mathrm{~cm}^{-3}$ in the material, which is an order of magnitude greater than the Er concentration. The addition of extra oxygen results in a significant decrease in the $\mathrm{Er}^{3+}$ related luminescence. This reduction in $\mathrm{Er}^{3+}$ emission was observed in all films implanted with oxygen.

\section{DISCUSSION}

The development of an efficient and reliable Er dopant source for use in the MOVPE process requires an understanding of the effect of growth conditions and source reactivity on dopant incorporation. A variety of cyclopentadienyl compounds with differing alkyl ligand substituents have been used for Er doping, and their usefulness has generally been evaluated based on their vapor pressure and Er incorporation efficiency. Although the ligand structure strongly affects the compound volatility, the results of this study suggest that source chemistry plays a larger role in the Er doping process. The growth dependencies of Er doping are very similar to those obtained with cyclopentadienyl Mg dopant sources, indicating that these sources may follow similar routes in their surface or gas phase decomposition reactions.

Er doping exhibits an approximate square-law dependence on the mole fraction of $\mathrm{Er}$ in the inlet gas stream using either ( $t$-butylCp $)_{3} \mathrm{Er}$ or ( $i$-propylCp) ${ }_{2} \mathrm{CpEr}$. A second order dependence on inlet mole fraction has also been reported in studies of $\mathrm{Mg}$ doping of GaAs from $\mathrm{Cp}_{2} \mathrm{Mg}^{16-18}$ and (methylCp) ${ }_{2} \mathrm{Mg}^{19}$ sources. Higher order doping dependencies can result when multiple dopant source molecules are involved in the rate-limiting step to dopant incorporation. The fact that a second-order dependence was obtained for both $\mathrm{Er}$ and $\mathrm{Mg}$ doping suggests that the cyclopentadienyl chemistry is responsible for this effect. Er doping is independent of growth temperature using either ( $t$-butylCp) ${ }_{3} \mathrm{Er}$ or ( $i$-propylCp $)_{2} \mathrm{CpEr}$. Similar behavior has been reported for Er doping of GaAs and InP using $\mathrm{Cp}_{3} \mathrm{Er}$ and (methylCp) ${ }_{3} \mathrm{Er}$ sources. ${ }^{4} \mathrm{Mg}$ doping from $(\mathrm{Cp})_{2} \mathrm{Mg}$ is also temperature insensitive at low growth temperatures, but decreases rapidly with increasing temperature above $\sim 700{ }^{\circ} \mathrm{C} .{ }^{16}$ The temperature dependence of $\mathrm{Mg}$ doping is due to the high elemental vapor pressure of $\mathrm{Mg}\left(12\right.$ Torr at $\left.727^{\circ} \mathrm{C}^{20}\right)$ which limits doping at high growth temperatures due to $\mathrm{Mg}$ desorption from the growth surface. This effect is not observed with $\mathrm{Er}$ due to its low vapor pressure $\left(2.6 \times 10^{-8}\right.$ Torr at $\left.727^{\circ} \mathrm{C}^{21}\right)$, therefore, Er doping remains insensitive to temperature over the entire range of growth conditions.

The $(i \text {-propy } \mathrm{Cp})_{2} \mathrm{CpEr}$ and $(t \text {-butylCp })_{3} \mathrm{Er}$ sources have identical dependencies on growth temperature and inlet mole fraction, but significantly different dependencies on the V/III ratio. The Er concentration was independent of the V/III ratio with ( $i$-propylCp $)_{2} \mathrm{CpEr}$, but dropped off dramatically with increasing V/III using ( $t$-butylCp) ${ }_{3}$ Er. The nature of this strong dependence on $\mathrm{AsH}_{3}$ concentration has not been conclusively identified but a plausible explanation may be that prereaction of ( $t$-butylCp) ${ }_{3} \mathrm{Er}$ and $\mathrm{AsH}_{3}$ is occurring upstream of the susceptor which depletes the supply of Er to the growth surface. The exact nature of the interaction of these compounds with $\mathrm{AsH}_{3}$ requires further investigation. These results, however, show that Er doping efficiency is dependent on the cyclopentadienyl ligand structure and can be increased by using sources such as ( $i$-propylCp $)_{2} \mathrm{CpEr}$ that do not exhibit a dependence on the $\mathrm{AsH}_{3}$ concentration.

Er doping is further complicated by the high reactivity of Er with oxygen bearing compounds. Undoped GaAs and AlGaAs layers grown in our MOVPE system typically contain low or negligible levels of oxygen. Equivalent amounts of Er and oxygen, however, were measured in our Er-doped $\mathrm{GaAs}$ layers, indicating that the Er source efficiently getters oxygen from the growth environment incorporating it into the film. Possible sources of oxygen include contaminants in the Er source itself, or trace levels of water or oxygen within the growth system. The incorporation of oxygen in as-grown Er-doped $\mathrm{GaAs}$ grown by MOVPE was also reported by $\mathrm{Ta}-$ kahei and Taguchi. ${ }^{22}$

The high oxygen content of our films suggests that the majority of Er dopants may be present as Er-O complexes. The role of oxygen in Er-doped semiconductors is not, however, clear at this point. Previous studies of Er-doped $\mathrm{Si}^{23,24}$ and $\mathrm{Al}_{x} \mathrm{Ga}_{1-x} \mathrm{As}^{13,23,24}$ report increased $\mathrm{Er}^{3+}$ luminescence intensity when oxygen is added to the material through ion implantation. The origin of this enhancement is not known, but has been suggested to arise in Si:Er from the formation of $\mathrm{Er}-\mathrm{O}$ complexes or precipitates ${ }^{23}$ and in $\mathrm{Al}_{x} \mathrm{Ga}_{1-x} \mathrm{As}: \mathrm{Er}$ from Al-O-Er complexes. ${ }^{13}$ These Er-O-based complexes are thought to function as the primary $1.54 \mu \mathrm{m}$. luminescence centers. Conflicting results have been reported for oxygen codoping of GaAs:Er layers. Oxygen implantation into GaAs:Er films ${ }^{13}$ was found to reduce $\mathrm{Er}^{3+}$ emission intensity, but increased intensity was recently reported for GaAs:Er layers grown by MOVPE in an oxygen-containing ambient. ${ }^{22}$ Substantial amounts of oxygen are incorporated in our asgrown GaAs:Er layers, yet intense $\mathrm{Er}^{3+} \mathrm{PL}$ emission is still obtained. A significant decrease in $\mathrm{Er}^{3+}$ luminescence occurs, however, when extra oxygen is added to our MOVPE grown GaAs:Er films through ion implantation and annealing. The formation of Er-O complexes during growth may be a key to increase $\mathrm{Er}^{3+}$ luminescence efficiency in GaAs. The addition of oxygen to the MOVPE growth ambient provides ample opportunities for reaction with $\mathrm{Er}$ in the gas phase or on the growth surface. Er-O formation via ion implantation, however, relies on diffusion and is strongly dependent on annealing conditions. Defects remaining as residual ion implantation damage after annealing also serve to reduce luminescence efficiency. The formation and structure of $\mathrm{Er}-\mathrm{O}$ complexes during MOVPE growth would be expected to vary depending on reactor or growth conditions. The improvements in $\mathrm{Er}^{3+}$ luminescence reported to occur with decreasing growth temperature and V/III ratio, in Er-doped GaAs layers grown by MOVPE, ${ }^{9}$ are likely due to increased Er-O formation favored by such growth conditions. Analogous behavior has been reported for oxygen incorporation in $\mathrm{Al}_{x} \mathrm{Ga}_{1-x}$ As layers. ${ }^{25}$

Electrical measurements of $n$-type GaAs films codoped with $\mathrm{Er}$ and $\mathrm{Si}$ show the presence of donor compensating deep levels which originate from the Er doping process. Electrical compensation of shallow donors has also been observed in a previous study of $\mathrm{Er}$ doped $\mathrm{III}-\mathrm{V}$ semiconductors. ${ }^{26}$ The compensation ratio, $r=\left(n_{\text {no Er }}-n_{\mathrm{Er}}\right) /[\mathrm{Er}]$, 
is nearly unity at low Er doping levels in our GaAs:Si:Er. At higher Er concentrations, the compensation ratio is reduced, becoming $r \approx 0.01$ at an Er concentration of $2 \times 10^{18} \mathrm{~cm}^{-3}$. Er appears to be incorporating as a deep level impurity up to a concentration of $-2 \times 10^{17} \mathrm{~cm}^{-3}$, after which it is in an electrically inactive form under our limited range of growth conditions. The $12 \mathrm{~K}$ photoluminescence spectra of $\mathrm{FaAs}$ films codoped with $\mathrm{Er}$ and $\mathrm{Si}$ provides further evidence of the presence of deep levels associated with Er doping. An intense emission band from 0.88 to $0.90 \mu \mathrm{m}$ was observed in $\mathrm{GaAs}$ films codoped with both $\mathrm{Si}$ and $\mathrm{Er}$. The peak energies at $1.377 \mathrm{eV}(0.90 \mu \mathrm{m})$ and $1.409 \mathrm{eV}(0.88 \mu \mathrm{m})$ are not found in MOVPE GaAs:Si. Si-related defect peaks have been reported for non-Er-doped $\mathrm{GaAs}$ at $1.22 \mathrm{eV}$, for a gallium vacancy-Si $i_{\mathrm{Ga}}$ donor-acceptor complex, ${ }^{27}$ or $1.484 \mathrm{eV}$, for $\mathrm{Si}$ acceptor emission. ${ }^{28}$ The 0.88 and $0.90 \mu \mathrm{m}$ peaks are also not present in the PL spectra of GaAs:Si layers grown under similar conditions, indicating that they are associated with the Er dopants.

Deep levels associated with Er are believed to play an important role in rare-earth excitation, yet little is known about their origin or dependence on the growth process. It has been proposed that the excitation of Er in III-V semiconductors proceeds via the recombination of excitons bound to an Er-related hole or electron trap. ${ }^{29,30}$ The compensation of shallow donors observed in our GaAs:Er, Si layers suggests the presence of electron traps. Electron traps with activation energies of 0.65 and $0.67 \mathrm{eV}$ have been measured in MBEgrown. GaAs:Er using photocurrent induced transient spectroscopy. ${ }^{31}$ Hole traps have also been detected using deep level transient spectroscopy in $\mathrm{Er}$ ion-implanted GaAs. ${ }^{30}$ The microscopic nature of the decp center, however, has not been addressed. The results of this study suggest that a high concentration of Er-O complexes exist in our MOVPE-grown GaAs:Er layers. The incorporation of Al-O species in MOVPE GaAs during growth has previously been shown to introduce deep levels which compensate shallow donors $^{32}$ and $\mathrm{Er}-\mathrm{O}$ introduced into GaAs might be expected to act in a similar manner. Er-O complexes, therefore, may act as more efficient luminescence centers in GaAs due to an associated deep state.

\section{CONCLUSIONS}

The incorporation of Er during the MOVPE growth of $\mathrm{GaAs}$ was investigated through a study of the effect of the Er cyclopentadienyl source and MOVPE growth conditions on the Er doping process. Controlled incorporation of optically active $\mathrm{Er}^{3+}$ into GaAs was achieved using both $(t \text {-butylCp })_{3} \mathrm{Er}$ and $(i \text {-propylCp })_{2} \mathrm{CpEr}$ sources at a relatively low Er bubbler temperature of $90^{\circ} \mathrm{C}$. The $(i \text {-propylCp })_{2} \mathrm{CpEr}$ source results in an Er doping level an order of magnitude greater than is obtained with ( $l$-butylCp) ${ }_{3}$ Er. Er doping increases superlinearly with source mole fraction, and is insensitive to growth temperature due to the low elemental vapor pressure of Er and the low decomposition temperature of the Er source materials. This behavior is similar to that reported for cyclopentadienyl $\mathrm{Mg}$ dopants, indicating that cyclopentadienyl-based sources follow similar surface and gas phase decomposition pathways.
The strong affinity of the rare-earth compounds to oxygen complicates the Er doping process with respect to the formation of uptically active Er. Oxygen is incorporated in Er-doped GaAs films at an amount equivalent to the Er concentration in our material, indicating that the majority of $\mathrm{Er}$ atoms likely exist as Er-O complexes. Despite the high concentration of oxygen in the films, intense $\mathrm{Er}^{3+} \mathrm{PL}$ emission is observed suggesting that the Er-O complexes function as efficient luminescent centers. The addition of increased amounts of oxygen through ion implantation, however, results in a decrease in the $\mathrm{Er}^{3+}$ luminescence, similar to previous reports.

A decrease in the electron concentration was observed in $\mathrm{GaAs}$ films codoped with $\mathrm{Si}$ and $\mathrm{Er}$, indicating the presence of deep level centers associated with Er doping. The $12 \mathrm{~K}$ photoluminescence spectra of GaAs:Er, Si films contain a broad emission band near $0.90 \hat{\mu} \mathrm{m}$, providing further evidence of deep states. The same Er-O complexes are suggested as a possible source of these compensating deep centers.

\section{ACKNOWLEDGMENTS}

This research was supported by Strategic Defense Initiative/Innovative Science and Technology and managed by the Lewis Research Center, National Aeronautics and Space Administration. The authors would like to thank Frank Cardone at IBM and Dr. Steve Novak at Evans East for SIMS analysis of the Er-doped GaAs samples. Financial support of the National Science Foundation through Grant DMR-9106633 is also gratefully acknowledged.

'F. Bantien, B. Bauser, and J. Weber, J. Appl. Phys. 61, 2803 (1987).

${ }^{2}$ G. S. Pomrenke, H. Ennen, and W. Haydl, J. Appl. Phys. 59, 601 (1986).

${ }^{3}$ H. Ennen, J. Wagner, H. D. Muller, and R. S. Smith, J. Appl, Phys. 61; 4877 (1987).

${ }^{4}$ K. Uwai, H. Nakagome, and K. Takahei, Appl. Phys: Lett. 51, 1010 (1987).

${ }^{5}$ F. Scholz, J. Weber, K. Pressel, and A. Dornen, Mater. Res. Soc. Symp. Proc. 301, 3 (1993).

${ }^{6} \mathrm{~K}$. Takahei, H. Nakagome, T. Tanaka, and N. Honma, Chemtronics 5, 159 (1991).

${ }^{7}$ K. Uwai, H. Nakagome, and K. Takahei, J. Cryst. Growth 93, 583 (1988).

${ }^{8}$ M. L. Timmons, P. K. Chiang, and S. V. Hattangady, J. Cryst. Growth 77, 37 (1986).

${ }^{9}$ H. Nakagome, K. Uwai, and K. Takahei, Appl. Phys. Lett. 53, 1726 (1988).

${ }^{10}$ J. Weber, M. Moser, A. Stapor, F. Scholz, G. Bohnert, A. Hangleiter, A. Hammel, D. Wiedmann, and J. Weidlein, J. Cryst. Growth 104, 815 (1990).

${ }^{11}$ D. W. Langer, Y. and Li, X. M. Fang, and V. Conn, Mater. Res. Soc. Symp. Proc. 301, 15 (1993).

${ }^{12}$ The vapor pressure of $(i \text {-propylCp })_{2} \mathrm{CpEr}$ is estimated as $\sim 0.1$ Torr at $150^{\circ} \mathrm{C}$.

${ }^{13}$ J. E. Colon, D. W. Elsaesser, Y. K. Yeo, R. L. Hengehold, and G. S. Pomrenke, Appl. Phys. Lett. 63, 216 (1993).

${ }^{14}$ E. Veuhoff, T. F. Kucch, and B. S. Meyerson, J. Elcctrochem. Soc. 132, 1958 (1985).

${ }^{15}$ M. E. Greiner and J. F. Gibbons, Appl. Phys. Lett. 44, 750 (1984).

${ }^{16}$ P. J. Wang, T. F. Kuech, M. A. Tischler, P. Mooney, G. Scilla, and F. Cardone, J. Appl. Phys. 64, 4975 (1988).

${ }^{17}$ C. R. Lewis, W. T, Kietze, and M. J. Ludowise, J. Electron. Mater. 12, 507 (1983).

${ }^{18}$ M. Rask, G. Landgren, S. G. Andersson, and A. Lundberg, J. Electron. Mater. 17, 311 (1988).

${ }^{14}$ P. Roetgen and H. Beneking, Inst. Phys. Conf. Ser. 79, 145 (1985). 
${ }^{20}$ Selected Values of the Thermodynamic Properties of the Elements, edited by R. Hultgren (American Society for Metals, Metals Park, OH, 1973), p. 297.

${ }^{21}$ Selected Values of the Thermodynamic Properties of the Elements, edited by Hultgren (American Society for Metals, Metals Park, OH, 1973), p. 168.

${ }^{22} \mathrm{~K}$. Takahei, and A. Taguchi, J. Appl. Phys. 74, 1979 (1993).

${ }^{23}$ P. N. Favennec, H. L'Haridon, D. Moutonnet, M. Salvi, and M. Gauneau, Jpil. J. Appl. Phys. 29, L524 (1990).

${ }^{24}$ J. Michel, J. L. Benton, R. F. Ferrante, D. C. Jocobson, D. J. Eaglesham, E. A. Fitzgerald, Y. H. Xie, J. M. Poate, and L. C. Kimerling, J. Appl. Phys. 70, 2672 (1991).

${ }^{25}$ T. F. Kuech, R. Potemski, F. Cardone, and G. Scilla, J. Electron. Mater. 21, 341 (1992).

${ }^{26}$ K. R. Evans, E. N. Taylor, C. E. Stutz, D. W. Elsaesser, J. E. Colon, Y. K.
Yeo, R. L. Hengehold, and J. S. Solomon, J. Vac. Sci. Technol. B 10, 870 (1992).

${ }^{27}$ E. W. Williams, Phys. Rev. 168, 922 (1968).

${ }^{28}$ D. J. Ashen, P. J. Dean, D. T. J. Hurle, J. B. Mullin, and A. M. White, J. Phys. Chem. Solids 36, 1041 (1975).

${ }^{29} \mathrm{~K}$. Takahei, A. Taguchi, H. Nakagome, K. Uwai, and P. S. Whitney, J. Appl. Phys. 66, 4941 (1989).

${ }^{30} \mathrm{~J}$. E. Colon, D. W. Elsaesser, Y. K. Yeo, R. L. Hengehold, and G. S. Pomrenke, Mater. Sci Forum 83-87, 671 (1992).

${ }^{31}$ T. Benyattou, D. Seghier, G. Bremond, S. Moneger, A. Kalboussi, G. Marrakchi, G. Guillot, C. L. Homer, B. Lambert, Y. Toudic, and A. LeCorre, Mater. Res. Soc. Symp. Proc. 301, 163 (1993).

${ }^{32}$ M. S. Goorsky, T. F. Kuech, F. Cardone, P. M. Mooney, G. J. Scilla, and R. M. Potemski, Appl. Phys. Lett. 58, 1979 (1991). 